\title{
MORE THAN WHAT MEETS THE EYE- DELAYED PRESENTATION OF ORBITAL FOREIGN BODY
}

\author{
Siddiqui Sarwat Fatima ${ }^{1}$
}

${ }^{1}$ Resident, Department of Ophthalmology, LTMMC, Sion, Mumbai.

HOW TO CITE THIS ARTICLE: Fatima SS. More than what meets the eye- delayed presentation of orbital foreign body. J. Evolution Med. Dent. Sci. 2017;6(43):3399-3400, DOI: 10.14260/Jemds/2017/736

\section{PRESENTATION OF CASE}

When a 28-year-old male presented to the Casualty with assault to right eye with a wooden stick within 2 hours of injury with complaints of pain, swelling, black eye and bleeding from lower lid.

On examination, his general condition was stable with a vision of $6 / 9$ with pupils reacting to light. Both lids had ecchymoses and oedema with a lower lid triradiate $[0.5 \mathrm{x} 0.5 \mathrm{x}$ $0.5 \mathrm{~cm}$ ] Contused Lacerated Wound (CLW) and a partial thickness tear of the temporal palpebral conjunctiva. Cornea, Ant. Chamber, Iris pattern, Lens status were within normal limits. Ocular tension and movements were within normal limit with an intact orbital margin and normal fundus examination. Other eye examination being normal.

Primary treatment was given in the form of suturing of CLW with 6 - 0 vicryl, Tetanus toxoid and a course of broadspectrum antibiotic. The partial thickness conjunctival tear was treated conservatively. X-ray of right eye orbit with antero-posterior and lateral views was advised and patient was asked to follow up with reports after 7 days.

Patient did not followup and presented directly after 3 weeks with complaints of increased pain, swelling of lower lid with an excrescence at the CLW site, vision of 6/9 improving to $6 / 6$ and healed conjunctival tear. Diagnosis of lower lid suture granuloma was made and a Computed Tomography (CT) scan of orbit was advised.

Visual acuity was recorded at 6/9 OD and 6/6 OS. Pupillary evaluation, intraocular pressures, ocular motility and fundus examination were normal. A conjunctival tear and an eyelid wound measuring $5 \mathrm{~mm} \times 5 \mathrm{~mm}$ noted on the lower lid were sutured. At two weeks followup, the patient returned with complaints of diplopia on upgaze. A CT scan showed a $22 \mathrm{~mm}$ long foreign body in close relation with the inferior rectus along the orbital floor causing an inflammatory reaction. An exploration was performed and the wooden foreign body was removed through the skin incision. Post-operatively, the inflammation subsided with no residual diplopia.

Financial or Other, Competing Interest: None. Submission 10-04-2017, Peer Review 16-05-2017, Acceptance 22-05-2017, Published 29-05-2017.

Corresponding Author:

Dr. Siddiqui Sarwat Fatima

\#501, 5th Floor

Evershine Woods, Building No. 1,

Opp. Gaurav City,

Beverly Park,

Mira Road (East), Thane-401107.

E-mail: sarwat.fatima.khaled18@gmail.com DOI: $10.14260 /$ jemds/2017/736

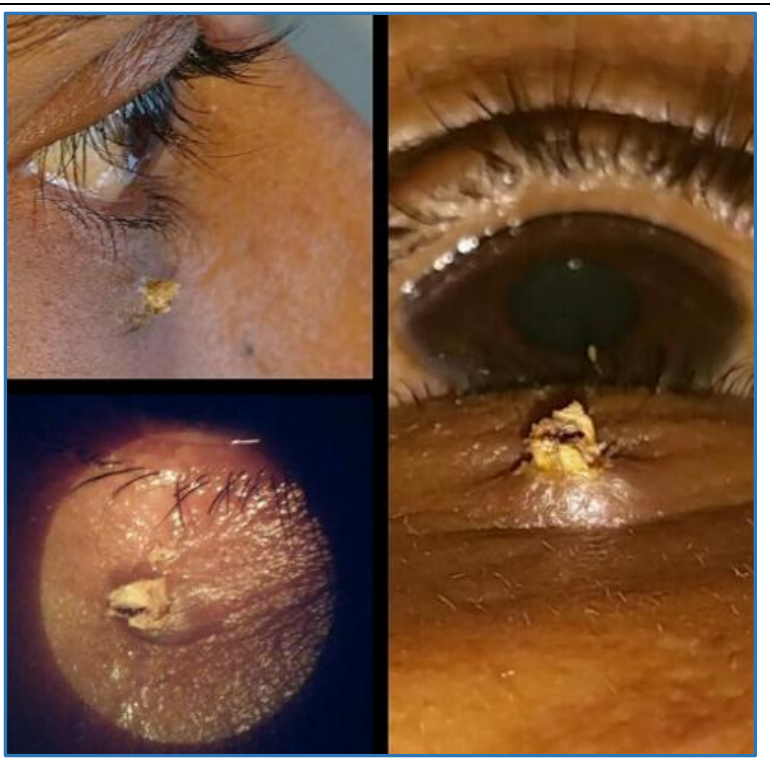

Figure 1. Clinical Images and Slit Lamp showing the Wooden Foreign Body

A month later from the initial injury, patient noticed something protruding from the CLW site. On examination patient had diplopia in up and down gaze, an enophthalmos of $2 \mathrm{~mm}$ with restricted occular movements in levo and dextro elevation and depression and a PFH difference of $2 \mathrm{~mm}$ between the two eyes.

\section{On Closer Examination}

There was the wooden foreign body trying to extrude out from the CLW site, which was confirmed on slit lamp and for detailed study a CT scan of the orbit was adviced, which showed a $2.2 \mathrm{~cm}$ hyperdense foreign body [+107 HU] with partial inf. rectus entrapment.

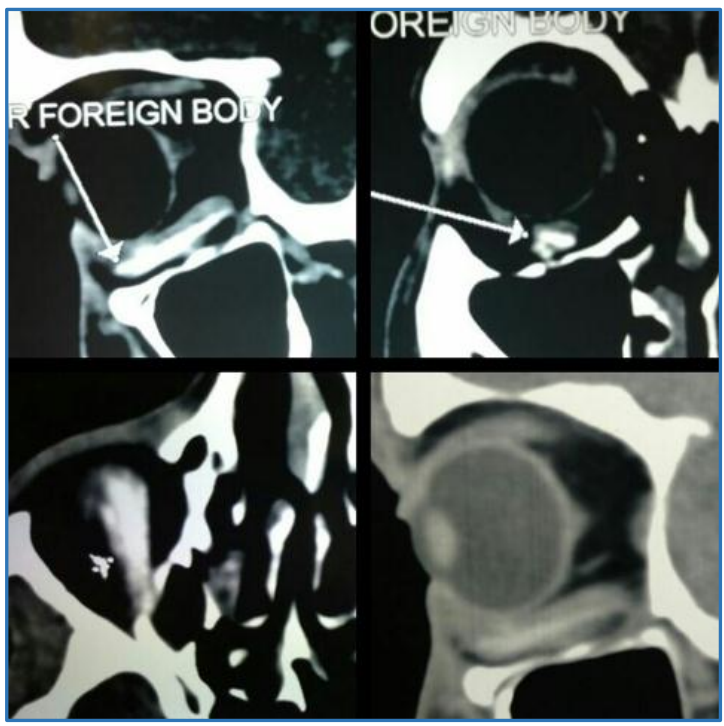

Figure 2. CT Scan of the Orbit showing the Wooden Foreign Body 


\section{DISCUSSION OF MANAGEMENT}

Orbital exploration was planned under general anaesthesia. A Transconjunctival Orbitotomy was done through an incision based in the inferior fornix to decrease chances of a scar. Blunt dissection was done to separate the foreign body from the surrounding soft tissue. The foreign body was then grasped with the help of artery forceps and was removed completely. The wound track was explored for any remnants of the wooden piece. The Inferior Rectus muscle showed minimal fibrosis.

Post-operatively, patient recovered well with greatly improved ocular movements and a minimal residual enophthalmos due to the Inferior Rectus muscle fibrosis.

Orbital trauma is one of the most challenging and difficult to manage of the ophthalmic spectrum. The clinical presentation of an orbital foreign body is variable. Management and prognosis depend on the composition, location of the object and presence or absence of secondary infection. Metallic objects and glass particle foreign bodies are the most frequently encountered and well-tolerated, whereas organic foreign bodies elicit an inflammatory reaction and lead to serious complications. Despite modern imaging methods, it is often difficult to identify and locate organic intraorbital foreign bodies. Surgical removal is mandatory to save vision and prevent sequelae. It is imperative to maintain a high index of suspicion in such cases to avoid misdiagnosis.

A variety of orbital foreign bodies have been reported in the literature. These include glass, stone, metal, wood, graphite, button, faucet handle, fish jaw, iron hat peg, chopstick, pencil, large wooden plank, pocket knife, meat hook and pitchfork. ${ }^{(1,2)}$ In general, a penetrating orbital foreign body injury may be categorised either as a low-velocity or highvelocity injury with majority of them falling in the first category. Young people appear to have a propensity to these injuries with history of assault being the commonest that we have observed, and children tend to get injured by falling onto a sharp object like pencil.(3) Most eye injuries involving the penetration of a foreign body exhibit minimal surface damage, which may often be undervalued by the physician during the initial evaluation. Orbital fat tends to conceal the trajectory, making it difficult to identify a point of entry. Thus, suspicion is crucial for defining the diagnosis.(2)

The possibility of a foreign body should be considered following a history of trauma with persistent signs of inflammation, limited eye movement, delayed healing or deterioration of the vision as was seen in our case. The cause of limited eye movement should be assessed with care, as it may have been caused by the presence of a foreign body, trauma to the oculomotor, trochlear and abducent nerves or muscle impingement in fractured bones in the orbital walls. (4)

Wooden foreign bodies are particularly liable to fragment, both on impalement and withdrawal which makes their removal a particular challenge. They are soft and may have many soil-borne bacteria, hence infection is a risk even if a small fragment is left inside the wound.(5) Those that penetrate the orbit must be removed completely in a controlled manner with meticulous haemostasis. Their vigorous removal may further damage the globe and cause loss of the tamponade effect stressing the need for good access for haemostasis.
Computed tomographic imaging relies on the differing radiodensities of tissues for their differentiation. The radiodensity of wood is variable and may be similar to that of the orbital tissues, which may account for the difficulty in recognising as well as localising the foreign body. The CT appearance of wooden foreign bodies is related to the interval between injury and examination. The wooden foreign body may appear differently on CT scan depending upon the presentation. In the acute stage the very low density of wood can be confusing with low window settings, mimicking air bubbles. A wide window width (up to 2,000 HU) can be helpful for differentiating foreign bodies from air. In the subacute stage, wood assumes a moderate density and may be difficult to distinguish from surrounding orbital fat. In the chronic stage, the density of wood can become higher than that of orbital muscle. It may be associated with a foreign body reaction, which appears as a homogeneous mass surrounding the dense wooden foreign body with a density similar to the adjacent extraocular muscles.(6) Also the radiological appearance of dry wood on CT scanning is similar to that of air and the appearance of hydrated wood is similar to that of soft tissue, rendering detection more difficult.(7) Magnetic resonance imaging, which depends on the density of protons in the tissue and their different relaxation times is better for localising the wooden foreign bodies. These properties of wood are dissimilar enough from those of the soft tissue to allow differentiation.(6) Therefore, in cases where there is strong suspicion of wooden foreign body and the CT scan is not conclusive, MRI should be done. However, as a primary investigation the role of MRI is debatable.

A detailed history with thorough wound exploration, a CT scan before suturing a CLW and MRI in CT scan negative cases of suspicion can all prove to be stitches in time which can save nine.

\section{FINAL DIAGNOSIS}

Intraorbital Wooden Foreign Body.

\section{REFERENCES}

[1] Singh BH, Khan VV. Wooden foreign body in orbit: endoscopic removal. International Journal of Otorhinology and Opthalmology 2016;2(2):24-7.

[2] Bullock JD, Warwar RE, Bartley GB, et al. Unusual orbital foreign bodies. Ophthal Plast Reconstr Surg 1999;15(1):44-51.

[3] Miller CF, Brodkey JS, Colombi BJ. The danger of intracranial wood. Surg Neurol 1977;7(2):95-103.

[4] Macrae JA. Diagnosis and management of a wooden orbital foreign body: case report. Br J Ophthamol 1979;63(12):845-51.

[5] Specht CS, Varga JH, Jalali MM, et al. Orbitocranial wooden foreign body diagnosed by magnetic resonance imaging. Dry wood can be isodense with air and fat by computed tomography. Surv Ophthalmol 1992;36(5):341-4.

[6] Dass AB, Ferrone PJ, Chu YR, et al. Sensitivity of spiral computed tomography scanning for detecting intraocular foreign bodies. Ophthalmology 2001;108(12):2326-8.

[7] Cartwright MJ, Kurumety UR, Frueh BR. Intraorbital wood foreign body. Ophthal Plast Reconst Surg 1995;11(1): 44-8. 